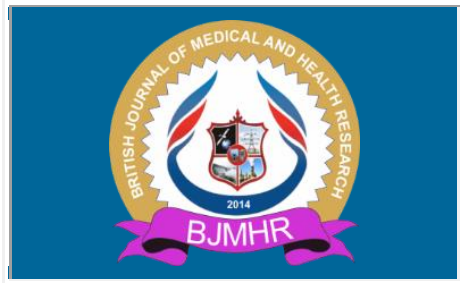

\title{
BJMHR
}

British Journal of Medical and Health Research

Journal home page: www.bjmhr.com

\section{Pre-Clinical Medical Students' Perception regarding Patient Safety in Primary Care}

\section{Firdous Jahan*, Maryann Radiance Aguiar, Diana Alshehabi, Fatema Sadiq Mahdi} 1.Oman Medical College Sohar, Oman

\begin{abstract}
Patient safety is a new and challenging discipline in primary care. Medical students need to understand and demonstrate appropriate patient safety skills in professional education. Preclinical students at Oman Medical College (OMC) have clinical skills training in primary care as well as in the hospital. The present study aimed to seek pre-clinical medical students' perceptions of their individual performance at a range of safety skills. A cross sectional study conducted at OMC. Data was collected by self-administrated questionnaire to a simple random sample of 50 medical students in pre-clinical years after finishing Family Medicine rotation. Data was analyzed using Statistical Package for Social Sciences (SPSS) version 20.0. Most participants (88\%) agreed the importance of patient safety. Self- rated general knowledge on patient safety on good level (72\%) compared to $(27 \%)$ for the specific knowledge issues score. In medical error management $75 \%$ willing to report medical errors, more than half willing to disclose error to patient and faculty and $89 \%$ agreed introducing patient safety topic in undergraduate medical schools curricula. Students had a favorable opinion of their own safety skills. However, specific knowledge question revealed some misconceptions. Most participants recognized the importance of patient safety topic in curriculum. Students are fair and honest to report medical errors. They considered competent physician don't make errors.
\end{abstract}

Keyword: Patient safety, pre-clinical medical students, perception 


\section{INTRODUCTION}

Patient safety is the key how health care looks after for the patient. Every person working in the clinic has a role in patient safety, including a front-desk worker, medical assistant, registered nurse, physician, pharmacist, and laboratory technician and trainee medical students $^{1-2}$. Do no harm is the principle of medical practice and the first priority for any medical practitioner. Abbreviations and other shorthand notations on prescriptions and orders increase the risk of medication errors. World Health Organization has published the curriculum for medical students working in health care institution dealing with patient care $\mathrm{c}^{3-4}$. Patient safety is a new and challenging discipline in primary care. Among the challenges for patient safety improvement, education of medical students is intimidating ${ }^{5-6}$. Practice organization, culture, diagnostic errors, and medication safety have been found to be important areas for further improvement. Strategies for patient safety improvement in family practice might benefit from training and research on implementing Evidence-Based practice ${ }^{7-}$ 8

Patient safety in general practice is an issue of concern which must be recognized by medical schools that the importance of safe care ${ }^{9-10}$. Medical students will soon play key roles in frontline patient care, their preparedness for safe, reliable care provision is of special importance. Teaching of patient safety and quality improvement to medical students will be best received if it is integrated into clinical education rather than solely taught in pre-clinical lectures or through independent computer modules. The urgent need for patient safety education for healthcare students has been recognized by many accreditation bodies including $\mathrm{MOH}$ Oman ${ }^{11}$. The teaching of communication skills covering patient safety is embedded into the curriculum. In the preclinical year's students, have structured lectures on principles and theories of communication embedded within courses on Behavioral Medicine and Ethics. They also experience real scenarios at hospital rotation and primary health care clinics. Medical students need to understand and demonstrate appropriate patient safety skills early and continuously in their professional education and practice. The aim of this study was to identify the perception and knowledge of pre-clinical students regarding patient safety in primary care.

\section{MATERIALS AND METHOD}

A cross sectional study conducted at Oman Medical College in pre-clinical year. Data was collected by self-administrated questionnaire to a simple random sample of 50 medical students at $\mathrm{OMC}$ in pre-clinical years after finishing Family Medicine rotation. 
A structured questionnaire was designed after literature search and several brains storming sessions with the experts. The principal investigator ensured uniformity and two trained research assistants assisted principal investigator in data collection. The questionnaire comprised of two main sections. The first section consists of demographic details of the participants. Second section included Factors influencing patient safety general knowledge as well as specific knowledge and perception including importance of patient safety, cultural issue, problem solving, error management and attitudes towards teaching patient safety in curriculum. Data was analyzed using Statistical Package for Social Sciences (SPSS) version 20.0 .

\section{RESULTS AND DISCUSSION}

Most participants (88\%) agreed the importance of patient safety. Self- rated general knowledge on patient safety on good level $(72 \%)$ compared to $(27 \%)$ for the specific knowledge issues score In medical error management $75 \%$ willing to report medical errors, more than half willing to disclose error to patient and faculty $89 \%$ agreed introducing patient safety topic in undergraduate medical schools curricula.

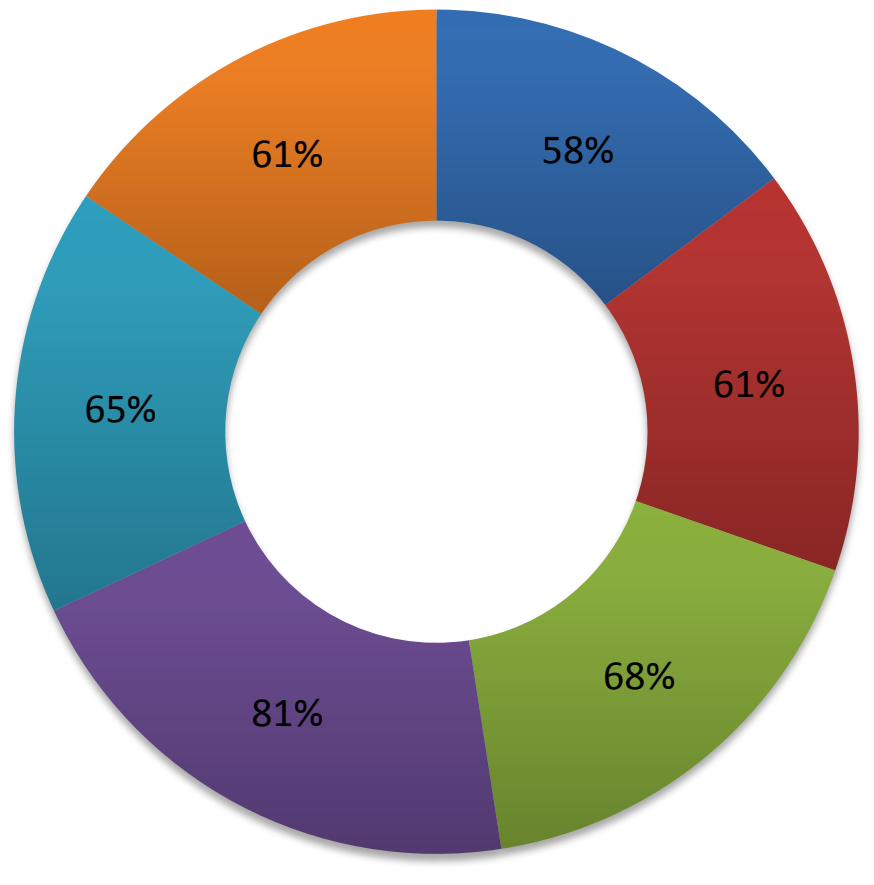

Patient safety is a global problem

Most clinical errors are preventable

Patient involvement is important

Root cause and risk analyses are effective in reducing mistakes.

Incident reporting reduces error

Good communication skills reduce error

Figure 1: Factors influencing patient safety knowledge- Agree 


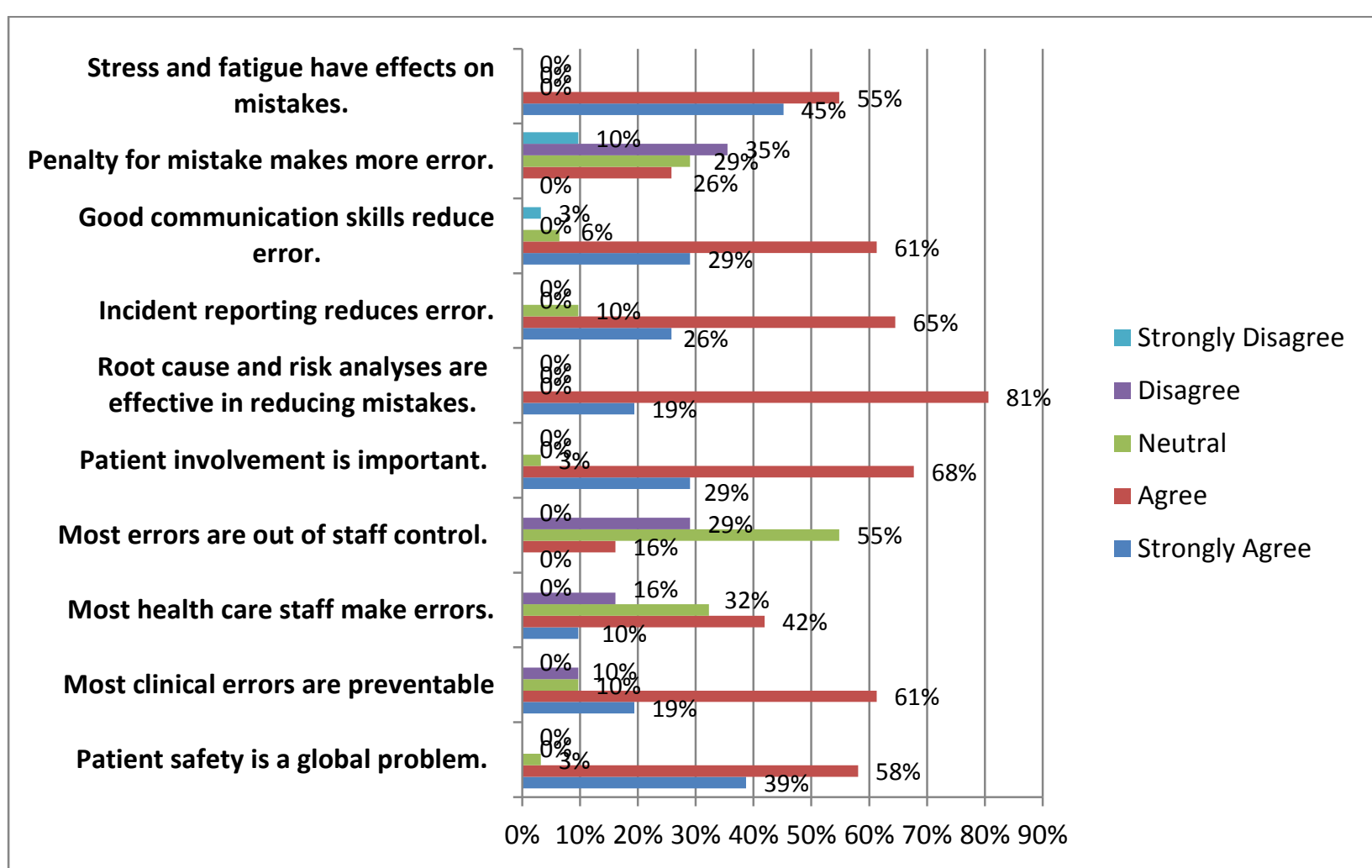

Figure 2: Patient safety knowledge and influencing factors

Long working hours/ time constrain.

Lack of education and training.

Patient load in Outpatient.

There is a gap between what physicians known as best care and what is being...

Most errors are due to things that physicians cannot do anything about.

Competent physicians do not make medical errors that lead to patient...

Patients play a role in preventing errors.

Competent physician dont make error.

Human error is not preventable.

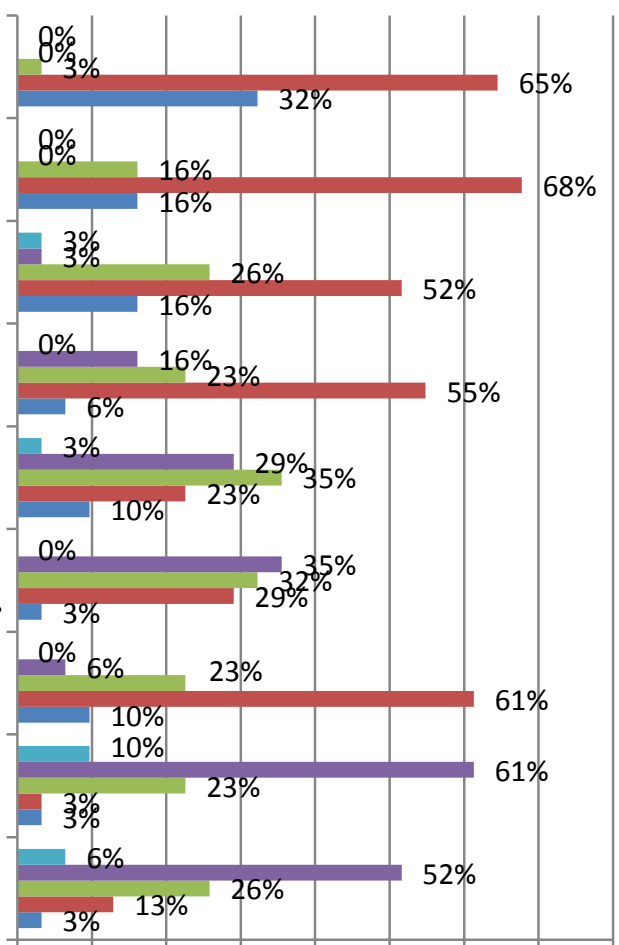

Strongly Disagree

Disagree

Neutral

Agree

- Strongly Agree

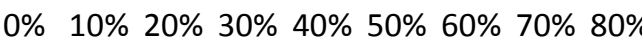

Figure 3: Causes of Error 


\section{Error Management and Problem Solving}

\begin{tabular}{|c|c|c|c|c|c|}
\hline & $\begin{array}{l}\text { Strongly } \\
\text { Agree }\end{array}$ & Agree & Neutral & Disagree & $\begin{array}{l}\text { Strongly } \\
\text { Disagree }\end{array}$ \\
\hline $\begin{array}{l}\text { If I saw a medical error, I would } \\
\text { keep it to myself. }\end{array}$ & $0 \%$ & $6 \%$ & $0 \%$ & $55 \%$ & $39 \%$ \\
\hline $\begin{array}{l}\text { Physicians should not tolerate } \\
\text { uncertainty in patient care and } \\
\text { routinely report medical errors. }\end{array}$ & $16 \%$ & $68 \%$ & $10 \%$ & $3 \%$ & $3 \%$ \\
\hline $\begin{array}{l}\text { The culture of medicine makes it } \\
\text { easy for providers to deal }\end{array}$ & $3 \%$ & $45 \%$ & $39 \%$ & $13 \%$ & $0 \%$ \\
\hline constructively with errors. & & & & & \\
\hline $\begin{array}{l}\text { If there is no harm to a patient, } \\
\text { there is no need to address an error. }\end{array}$ & $0 \%$ & $13 \%$ & $6 \%$ & $68 \%$ & $13 \%$ \\
\hline $\begin{array}{l}\text { Only physicians can determine the } \\
\text { causes of a medical error. }\end{array}$ & $0 \%$ & $32 \%$ & $23 \%$ & $45 \%$ & $0 \%$ \\
\hline $\begin{array}{l}\text { Reporting systems do little to } \\
\text { reduce future errors. }\end{array}$ & $6 \%$ & $42 \%$ & $13 \%$ & $35 \%$ & $3 \%$ \\
\hline $\begin{array}{l}\text { After an error occurs, an effective } \\
\text { strategy is to work harder and to be } \\
\text { more careful. }\end{array}$ & $23 \%$ & $65 \%$ & $13 \%$ & $0 \%$ & $0 \%$ \\
\hline $\begin{array}{l}\text { Support peers who make un } \\
\text { intentional errors. }\end{array}$ & $16 \%$ & $39 \%$ & $16 \%$ & $16 \%$ & $13 \%$ \\
\hline $\begin{array}{l}\text { Do not blame peers for their own } \\
\text { mistakes. }\end{array}$ & $6 \%$ & $10 \%$ & $35 \%$ & $45 \%$ & $3 \%$ \\
\hline $\begin{array}{l}\text { Cooperate with staff to resolve } \\
\text { patient. }\end{array}$ & $32 \%$ & & $10 \%$ & $0 \%$ & $0 \%$ \\
\hline $\begin{array}{l}\text { Willing to share information about } \\
\text { clinical errors. }\end{array}$ & $10 \%$ & $65 \%$ & $19 \%$ & $6 \%$ & $0 \%$ \\
\hline $\begin{array}{l}\text { Do not hesitate to change practice } \\
\text { habits to improve patient safety. }\end{array}$ & $42 \%$ & $35 \%$ & $13 \%$ & $10 \%$ & $0 \%$ \\
\hline $\begin{array}{l}\text { Willing to report errors whether or } \\
\text { not patient was harmed. }\end{array}$ & $26 \%$ & $58 \%$ & $16 \%$ & $0 \%$ & $0 \%$ \\
\hline $\begin{array}{l}\text { No Fear from negative } \\
\text { consequences associated with } \\
\text { reporting errors. }\end{array}$ & $6 \%$ & $48 \%$ & $19 \%$ & $19 \%$ & $6 \%$ \\
\hline $\begin{array}{l}\text { Likely to disclose an error to the } \\
\text { nursing staff. }\end{array}$ & $6 \%$ & $29 \%$ & $39 \%$ & $26 \%$ & $0 \%$ \\
\hline $\begin{array}{l}\text { Likely to disclose an error to the } \\
\text { faculty. }\end{array}$ & $0 \%$ & $71 \%$ & $19 \%$ & $10 \%$ & $0 \%$ \\
\hline $\begin{array}{l}\text { Likely to disclose error to the } \\
\text { patient. }\end{array}$ & $10 \%$ & $48 \%$ & $39 \%$ & $3 \%$ & $0 \%$ \\
\hline
\end{tabular}


Learn about informed consent, patient autonomy and ethics.

Careful documentation and follow up should be done.

Patient safety is an important topic and

You would like to receive further...

Physicians should routinely spend part of their professional time working to...

Teaching should start in pre-clinical years.

Patient safety should be a routine work in clinics.

Teaching and Learning improves patient safety in medical school.

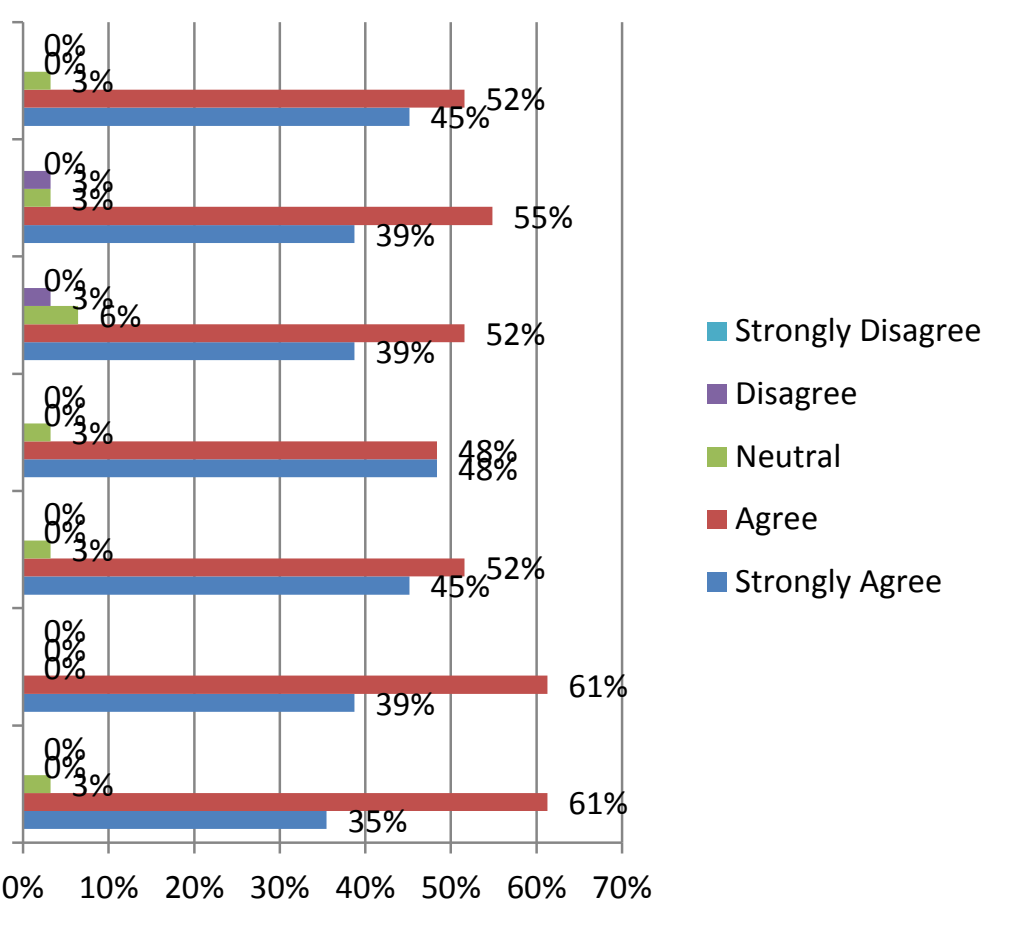

Figure 4: Regarding the attitude towards teaching patient safety to medical students:

\section{Education}

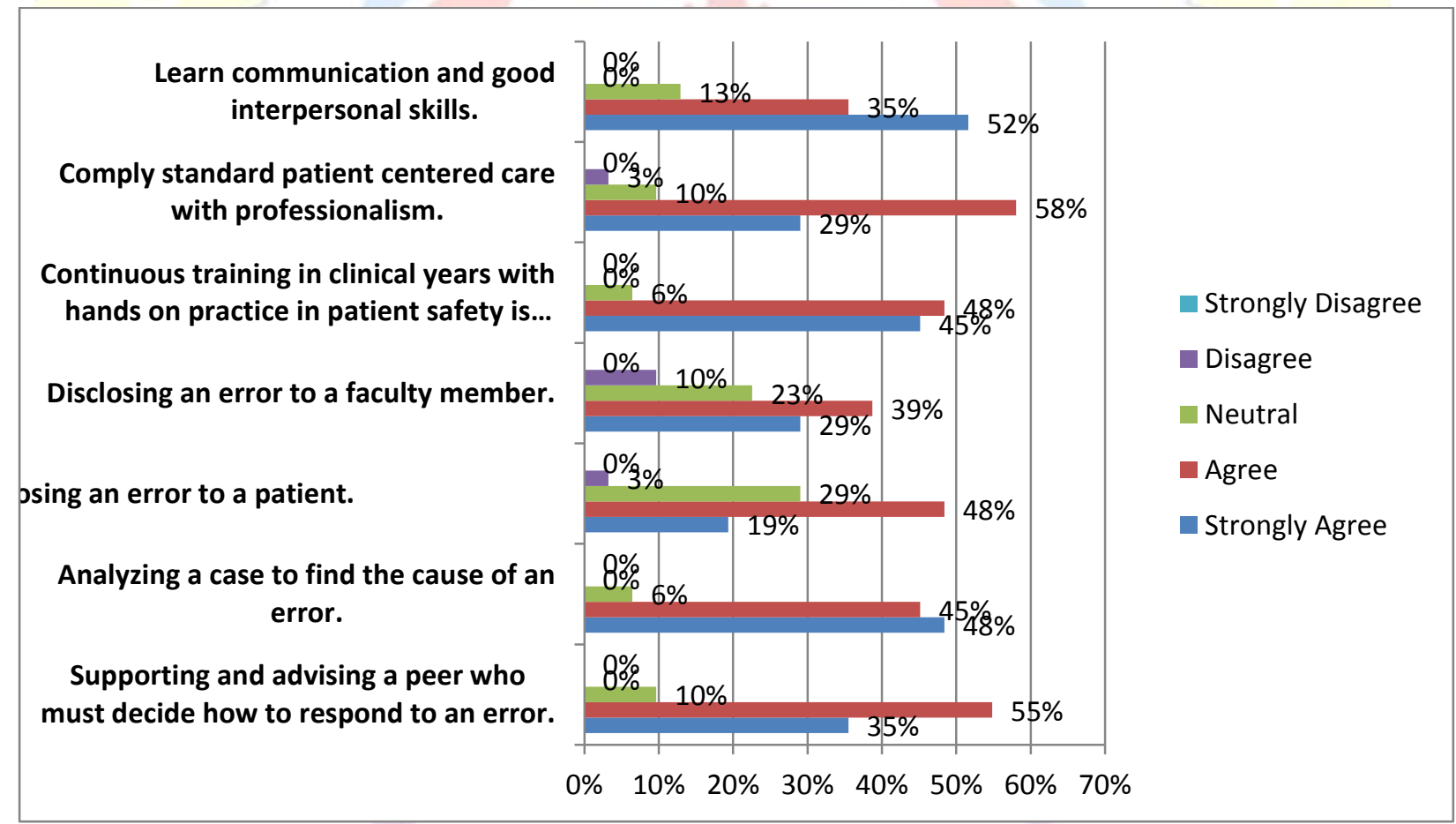

Figure 5: Regarding the attitude towards teaching patient safety to medical students:

Skills

\section{RESULTS AND DISCUSSION}

Developing a culture for patient safety in general practice could begin as early as in preclinical teaching in medical school. Primary care is a first contact of patient to health care professional, if patient safety issues are taught and made explicit to trainees during training 
than it is easy for a physician to comply with patient safety standards ${ }^{12}$. Primary care physicians must recognize that the provision of safe care in primary care must be patientcentered, and they must take into account patient values in the delivery of safe care ${ }^{13-14}$. Physicians are also encouraged to include patients in the decision-making processes that are related to safe care. Medical students will soon play key roles in frontline patient care, their preparedness for safe, reliable care provision is of special importance ${ }^{15}$. Majority of students had good general knowledge. However, students' perception of patient safety demonstrated a number of misconceptions.

In this study most participants (88\%) agreed the importance of patient safety in primary care. Similar result is published in literature that students has a favorable opinion of their own safety skills and importance of learning these skills ${ }^{16-17}$. In our study self- rated general knowledge on patient safety on good level $(72 \%)$ compared to $(27 \%)$ for the specific knowledge issues score (Fig I and 2). Literature reports the importance of knowledge of patient safety in medical students however, one study has shown that there is a measurable discrepancy between the students' perceived quality of their medical education and their feelings that they are well prepared to cope with severe clinical challenge ${ }^{18-19}$. In medical error management our one third students are willing to report medical errors, more than half willing to disclose error to patient and faculty (Fig 3). In medical error management most frequent strategies employed by students in patient safety, disclosing to faculty and patient, ensuring good communication with the patient. Most of the participants likely to disclose the error and showed willing to change habits to improve patient safety. The majority agreed to support peers who make unintentional errors and not to blame them for their own mistake. Medical errors result from poorly designed systems and processes is also an important factor other than human factor. Medical students are very positive regarding error management, nearly half of them have positive attitude towards disclosure of medical error and problem solving (Table I) ${ }^{20-21}$.

Medical students in pre-clinical years had agreement that teaching patient safety module should start early in clinical teaching (Fig 4). Leung has reported the implementation of a patient safety curriculum should be tailored to an institution's needs. ${ }^{22}$ In our study students agreed introducing patient safety module in undergraduate medical schools curricula and showing positive attitude towards teaching and learning to improve their skills (Fig5). Hwang reported that strengthening patient safety competencies, especially teamwork, of students is required in undergraduate healthcare curricula was very helpful and1-day inter professional patient safety education program may be a promising strategy ${ }^{23}$. Assessing student perceptions of safety culture highlighted important observations from their experiences in 
primary care visit. It is imperative to identify the areas for curricular development to enhance patient safety ${ }^{24}$.

\section{CONCLUSION}

Majority of students had good general knowledge. However, students' perception of patient safety demonstrated in specific knowledge question revealed some misconceptions. Students had a favorable opinion of their own safety skills as well as fair and honest to report medical errors. Most participants recognized the importance of teaching patient safety topic in curriculum as a module in clinical context. Medical students as a future doctors need to understand and demonstrate appropriate patient safety skills early in medical education training and continuously in their professional education.

\section{REFERENCES}

1. Institute of Medicine. To Err is Human: Building a Safer Health System. Washington, DC: National Academy Press; 2000.

2. Patient Safety Learning Systems: A Systematic Review and Qualitative Synthesis. Ont Health Technol Assess Ser. 2017 Mar 1;17 (3):1-23. eCollection 2017.

3. WHO. Patient Safety Curriculum Guide for Medical Schools. Available from: (http://www.who.int/patientsafety/education/curriculum/download/en/index.html). Accessed 25 Sept 2016.

4. García Elorrio E, Macchiavello D, Rodriguez V, Catalano Y, Corna G, Dahinten J, Ontivero M. Knowledge, beliefs and attitudes report on patient care and safety in undergraduate students: validating the modified APSQ-III questionnaire. Medwave. 2016 Dec 20;16 (11):e6809. doi: 10.5867/medwave.2016.11.6809.

5. Colet PC, Cruz JP, Cruz CP, Al-Otaibi J, Qubeilat H, Alquwez N. Patient Safety Competence of Nursing Students in Saudi Arabia: A Self-Reported Survey. Int J Health Sci (Qassim). 2015 Oct;9 (4):418-26.

6. Hayes AJ, Roberts P, Figgins A, Pool R, Reilly S, Roughley C, Salter T, Scott J, Watson S, Woodside R, Patel V. Improving awareness of patient safety in a peer-led pilot educational program for undergraduate medical students. Educ Health (Abingdon). 2014 May-Aug;27 (2):213-6. doi: 10.4103/1357-6283.143775.

7. Chaneliere M, Jacquet F, Occelli P, Touzet S, Siranyan V, Colin C .Assessment of patient safety culture: what tools for medical students? BMC Med Educ. 2016 Sep 29;16(1):255.

8. Wetzel AP, Dow AW, Mazmanian PE. Patient safety attitudes and behaviors of graduating medical students. Eval Health Prof. 2012 Jun;35 (2):221-38. doi: 10.1177/0163278711414560. Epub 2011 Jul 25. 
9. Republished paper: The WHO patient safety curriculum guide for medical schools. Postgrad Med J. 2011 Apr;87(1026):317-21. doi: 10.1136/pgmj.2009.036970rep.

10. Armitage G1, Cracknell A, Forrest K, Sandars J. Twelve tips for implementing a patient safety curriculum in an undergraduate programme in medicine. Med Teach. 2011;33 (7):535-40. doi: 10.3109/0142159X.2010.546449. Epub 2011 Feb 28.

11. Myung SJ, Shin JS, Kim JH, Roh H, Kim Y, Kim J, Lee SI, Lee JH, Kim SW.The patient safety curriculum for undergraduate medical students as a first step toward improving patient safety. J Surg Educ. 2012 Sep-Oct;69 (5):659-64. doi: 10.1016/j.jsurg.2012.04.012. Epub 2012 May 23.

12. Ackerman SL, Sarkar U, Tieu L, Handley MA, Schillinger D, Hahn K, Hoskote M. Meaningful use in the safety net: a rapid ethnography of patient portal implementation at five community health centers in California. J Am Med Inform Assoc. 2017 Mar 15. doi: 10.1093/jamia/ocx015. [Epub ahead of print]

13. Kim CW, Myung SJ, Eo EK, Chang Y. Improving disclosure of medical error through educational program as a first step toward patient safety. BMC Med Educ. 2017 Mar 4;17 (1):52. doi: 10.1186/s12909-017-0880-9.

14. Escher C, Creutzfeldt J, Meurling L, Hedman L, Kjellin A, Felländer-Tsai L.Medical students' situational motivation to participate in simulation based team training is predicted by attitudes to patient safety. BMC Med Educ. 2017 Feb 10;17 (1):37. doi 2017.

15. Raymond-Dufresne É, Brazil V, Johnson PL, Nielson TL. Pre-clinical medical students' perceptions of their patient safety skills in a simulated emergency department. Emerg Med Australas. 2016 Jun;28 (3):325-8. doi: 10.1111/17426723.12565. Epub 2016 Mar 15.

16. Blasiak RC, Stokes CL, Meyerhoff KL, Hines RE, Wilson LA, Viera AJ. A crosssectional study of medical students' knowledge of patient safety and quality improvement. N C Med J. 2014 Jan-Feb;75 (1):15-20.

17. Schmitz K, Lenssen R, Rosentreter M, Gross D, Eisert A.Wide cleft between theory and practice: medical students' perception of their education in patient and medication safety. Pharmazie. 2015 May;70 (5):351-4.

18. Dankbaar ME, Richters O, Kalkman CJ, Prins G, Ten Cate OT, van Merrienboer JJ, Schuit SC. Comparative effectiveness of a serious game and an e-module to support patient safety knowledge and awareness. BMC Med Educ. 2017 Feb 2;17 (1):30. doi: 10.1186/s12909-016-0836-5. 
19. Teigland CL, Blasiak RC, Wilson LA, Hines RE, Meyerhoff KL, Viera AJ. Patient safety and quality improvement education: a cross-sectional study of medical students' preferences and attitudes. BMC Med Educ. 2013 Feb 5;13:16. doi: 10.1186/1472-6920-13-16.

20. Hwang JI, Yoon TY, Jin HJ, Park Y, Park JY, Lee BJ. Patient safety competence for final-year health professional students: Perceptions of effectiveness of an inter professional education course. J Interprof Care. 2016 Nov;30 (6):732-738. Epub 2016 Oct 5.

21. Leung GK, Patil NG. Patient safety in the undergraduate curriculum: medical students' perception. Hong Kong Med J. 2010 Apr;16 (2):101-5.

22. Nabilou B, Feizi A, Seyedin H. Patient Safety in Medical Education: Students' Perceptions, Knowledge and Attitudes. PLoS One. 2015 Aug 31;10 (8):e0135610. doi: 10.1371/journal.pone.0135610. eCollection 2015.

23. Bowman C, Neeman N, Sehgal NL. Enculturation of unsafe attitudes and behaviors: student perceptions of safety culture. Acad Med. 2013;88 (6):802-10. doi: 10.1097/ACM.0b013e31828fd4f4.

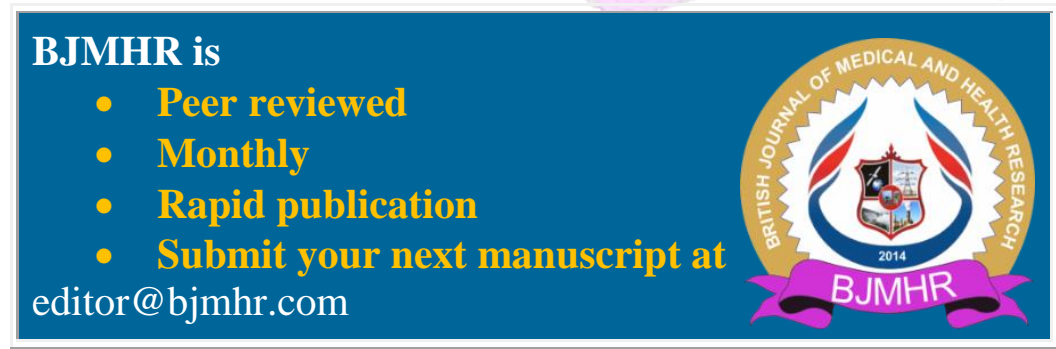

